DOI: 10.2478/ausfm-2019-0013

\title{
From Paragone to Symbiosis. Sensations of In-Betweenness in Sally Potter's The Tango Lesson
}

\author{
Judit Pieldner \\ Sapientia Hungarian University of Transylvania (Cluj-Napoca, Romania) \\ E-mail: pieldnerjudit@uni.sapientia.ro
}

\begin{abstract}
Sally Potter's The Tango Lesson (1997), an homage to the Argentine tango, situated in-between autobiography and fiction, creates multiple passages between art and life, the corporeal and the spiritual, emotional involvement and professional detachment. The romance story of filmmaker Sally Potter and dancer Pablo Verón is also readable as an allegory of interart relations, a dialogue of the gaze and the image, a process evolving from paragone to symbiosis. Relying on the strategies of dancefilm elaborated by Erin Brannigan (2011), the paper examines the intermedial relationship between film and dance in their cine-choreographic entanglement. Across scenes overflowing with passion, the film's haptic imagery is reinforced by the black-and-white photographic image and culminates in a tableau moment that foregrounds the manifold sensations of in-betweenness and feeling of "otherness" that the protagonists experience, caught in-between languages, cultures, and arts. ${ }^{1}$
\end{abstract}

Keywords: Sally Potter, dancefilm, intermediality, cine-choreography, tableau vivant, in-betweenness.

\section{Interpretive Approaches to Sally Potter's The Tango Lesson}

The Tango Lesson (1997), a highly personal declaration of love to dance and film allows a glimpse at both sides of the camera by employing the filmmaker Sally as the protagonist, a fictitious counterpart of the real-life Sally Potter. The film starts with Sally caught in the middle of a creative crisis in her London home as she is working on the scenes of a film project entitled Rage. To ease the pressure, Sally evades to Paris, where she chances upon a tango performance and decides

1 This work was supported by a grant of the Ministry of National Education, CNCS - UEFISCDI Romania, project number PN-III-P4-ID-PCE-2016-0418. 
to ask for tango lessons from Pablo, the other protagonist performing under the real name of the artist, Pablo Verón. The storyline unfolds in a series of numbered lessons. As Sally advances in the skill and feel of the tango, the relationship is carefully kept from becoming a sappy romance, while the entire film "dances" on the line in-between personal involvement and professional detachment. The conflict breaks out on the occasion of the only stage performance of the dance couple, when Sally fails to conform to the rule of the dance, according to which the female dancer should subject her motions to the lead of the male dancer. Hurt in his professional self-esteem, Pablo bursts out with anger: "You should do nothing when you dance. Just follow. Follow. Otherwise you block my freedom to move. You destroy my liberty. And then I cannot dance. I cannot dance. I can do nothing." The conflict deepens along the clash of professional positions in which both parties wish to be in control, and comes to a resolution in a sacred space, the Saint-Sulpice church in Paris, where Sally invites Pablo at dawn and they spontaneously enact a tableau vivant of Delacroix's Jacob Wrestling with the Angel. In Sally's interpretation, the painting becomes illustrative of their fight for dominance, and she invites Pablo to "follow" her in the process of filmmaking. Sally abandons her initial film project and starts working on a film about tango, nevertheless, it is difficult for Pablo to accept her in the role of the lead. While proceeding with the new film project, it is now Sally who gives lessons to Pablo on what it is like to look with the filmmaker's eyes. The viewer realizes that the film about to be made does not represent any sort of end product but the process itself. One of the culminating scenes is the magnificent tango in four, performed while Sally, Pablo and two further Argentinian dancers, Gustavo (Gustavo Naveira) and Fabián (Fabián Salas) are looking for a space to rent for their rehearsals in Buenos Aires. The film ends with the couple's reconciliation and spiritual communion through the joint experience of dancing and making film together.

The Tango Lesson gets finely attuned to a sort of simultaneously playful and subversive poetics that creates ambiguous passageways between autobiography and fiction. Anne Jerslev (2000) places this ambiguity within the principle of reflexivity that she identifies as the predominant strategy of the film, perceivable at the level of the singular instances of moving image as much as of the entire composition. At the level of image frames, the film abounds in écrans seconds - she borrows the term from Christian Metz's Les écrans seconds (1991) -, that is, reflexive framing, variations of frames within frames, which reinforce the scenic effect of the diegetic filmmaker's gaze. At the level of the entire structure, the narrative takes up the form of a doubling, in this way, "the film captures the viewer in an abysmal interpretative 
crisis or in the middle of a visual mise en abîme structure of inscrutability, surrounded by the director in front of and behind the camera" (Jerslev 2000, 277-278).

As the rules of tango are emphatically based on the lead of the male dancer, his steps being followed by his female partner, this form of dance powerfully encodes gender differences and thus provides a perfect ground for a film narrative driven by the issue of gender. Accordingly, the critical reception and theoretical discussion of The Tango Lesson is centred on the ways in which the film explores and deconstructs traditional patterns of gender, complementing the investigation of the female gaze, subjectivity and desire with psychoanalytic, phenomenological and postcolonial orientations (Guano 2004; Fowler 2009; Mayer 2009; Ince 2017). Kate Ince reads the entangled romance story between Sally and Pablo as an allegory of gender relations (Ince 2012). Although Sally Potter has never approved of being labelled a feminist, as an experimental artist, she belongs to the generation that grew up in the boom of feminist criticism in the 1970s, several tenets of which have often been found applicable to her life work. Accordingly, as Kate Ince's approach to Orlando and The Tango Lesson attests, the basic concepts and concerns of feminist phenomenology, namely the female subjectivity viewed through the lived body as well as the examination of the intricate relationship between the female body, motion and space can be efficiently brought into play in the discussion of these films. In examining "screen women as embodied subjects of their own experience and desire" (Ince 2017, 42), the focus is on agentic, embodied action and looking that reverse the stereotypical correlation of masculinity with looking and female subjectivity with "to-be-looked-at-ness." This can happen as both Orlando and Sally are powerful representatives of the agency of looking: the former through her overtly reflective direct address into the camera that playfully subverts diegesis; the latter through the reduplication, within the diegesis, of the female filmmaker's "camera eye" that delights in the spectacle of the male dancer's performance and also sees it as it will appear on screen (Ince 2017). [Fig. 1.] Thus, The Tango Lesson overthrows the gendered stereotypes of "woman as image, man as bearer of the look” as Laura Mulvey famously discusses visual pleasure in classical narrative cinema $(1999,837)$, and places the pleasure of looking on the female protagonist's side, being concerned with the dramatization of "a gaze that has the power to act out feminine desire, thus reclaiming woman's visual pleasure" (Guano 2004, 461). Catherine Fowler also discusses The Tango Lesson in the light of female desire: "as if in recognition for Potter's passion for the tango, The Tango Lesson marks a shift in Potter's practice as it fully addresses female desire. This shift can be explored further through a focus on our identification with Sally and her gaze, 
Pablo's narcissism, and the power struggle between the two that transforms into a spiritual yearning to be 'at home' with each other" $(2009,77)$.

\section{The Tango Lesson as an Allegory of Intermedial Relations}

Evidently, gender is not the exclusive concern of The Tango Lesson. At least to the same extent and in strong interconnection, it is also about arts, about the power struggle between dance and film as art forms striving for dominance, and about the transformation of this relationship resulting from their togetherness on the "dance floor" framed by the camera. Both a dancer and a filmmaker, Sally Potter elaborates in her film a thorough study of motion, as motion stands at the root of film and dance, allowing for a joint choreography of art forms as one art gains life through the other, being mutually dependent and inseparably intertwined. Although much has been said about the metacinematic and metacinematographic trouvaille of the film and the way dance creates its own space within (Jerslev 2000), The Tango Lesson has not been approached from the angle of intermediality. The protagonists' relationship models the relationship between the art forms they stand for, thus, we can also regard the film as an allegory of intermedial relations. Sally and Pablo's friendship, not devoid of conflicting moments, is formed in the course of the tango lessons and traces out the trajectory of a forming relationship between dance and film as a process evolving from paragone, rivalry between the arts to symbiosis that presupposes their organic interconnectedness.

The Tango Lesson is not just a "simple" dance film but rather one that tries to fathom the essence of film's mediality through dance. It can be read as a film experiment that probes the ways in which film can transcend its own medium by way of the other arts. Besides the atmosphere conveyed by the tango, the art of film gets accomplished through the complex sensation resulted from the lyrical tone, the subtle musical accompaniment, the mixed painterly and photographic, at times even sculptural quality of the crystal-clear black-andwhite images, all of which testify to Sally Potter's multimedia virtuosity. Sally Potter's contribution to the film as filmmaker, dance performer, choreographer, musician, singer and poet unifies media in one single body, performing a sort of “embodied intermediality" (Simonson 2013, 133). ${ }^{2}$ Her intermedial performance

2 The term is borrowed from Mary Simonson (2013), who uses it with reference to Rita Sacchetto's Tanzbilder, which were dance performances at the beginning of the twentieth century, tableaux vivants that revived paintings through motion and gesture. 
incorporated into her "multi-art cinema" (Mayer 2009, 3) marks out a symbolic site of media confluences.

The Tango Lesson well illustrates what it means to be intermedial. At this point, we should remember the distinction (made by Paech 2011 and Pethő 2011) between the intermediality of film and in film. The intermediality of film constitutes the inalienable specificity that defines film as a hybrid medium from the onset of cinema, the seventh art famously defined by Riciotto Canudo as being "a superb conciliation of the Rhythms of Space (the Plastic Arts) and the Rhythms of Time (Music and Poetry)" (2002 [1911], 11). The intermediality in film refers to the ways in which film interacts with other media incorporated in its medium, with the aim of exploring the media tensions and fusions that arise from this interaction. In this latter use of the concept of intermediality, Joachim Paech's clarification offers useful guidance: "intermediality is the introduction or repetition of a medium - as its form - 'in another, media form.' This assumes that in the same representation different forms can be observed which formulate, besides, different media properties" $(2011,15)$. An intermedial analysis of film is aimed at exploring the various forms in which the involved media leave their mark on the medium of film with their own media properties, at "employing techniques that tap into the multimedial complexity of cinema, exploiting the possibilities offered by the distinctive characteristics of the media components involved in the cinematic process of signification, and bringing into play the tensions generated by media differences" (Pethő 2011, 2).

Through the reflexive foregrounding of diverse media forms and orchestrating them into a highly stylized constellation, The Tango Lesson can be regarded not only as a study of motion, but also as an experiment in media interplays. In line with the specification that "the intermedial representation of a painting in a film will not contain the painting as such, but the formulation of its media qualities in the form of its representation in the other medium: film" (Paech 2011, 15), the paper proposes to demonstrate how dance as an art form impregnates the filmic expression, leaves its trace on the film medium and reflects its essence as a potential metacinematic metaphor. Through the reliance on the synergy of the other media and arts, The Tango Lesson devises a sort of "tango" of its own medium in the embrace of its "partner arts."

The film's accentuated intermediality may be regarded as being in strong correlation with the notion of transformation that lies at the heart of Sally Potter's artistic vision. The filmmaker herself assists the interpreters by stating that "I think the key word in my work is transformation" (Potter qtd. in MacDonald 
1995). Elsewhere she expounds on the idea, providing a synthesis of the principle and ethics that governs her entire oeuvre: "transformation is a key word in my films. There's an invitation to ask the questions: 'What do you see in other people, do you really see in them what they are? Who are you, what are you really?' You're not a fixed given. Take up the pen and write your own life or self-description: abandon it or explode it. You can change. That leads to the broader political principle: whole societies can change. It's an anti-despair way of thinking. Nothing's fixed, everything's impermanent, everything's in flux. We can influence events. Choice is involved - perhaps not a complete choice - but we can be part of the transformation at least" (Potter qtd. in Mayer 2009, 1). The Tango Lesson is also a story of transformation. The process of acquiring the skill of tango dancing implies change. The desire for the tango goes hand in glove with the desire for change. The film does not display dance as an end-product ready for stage, but focuses on the physical and spiritual transformation that the process of learning implies, not just about tango steps, but also about looking and seeing, about the self and the other. These thematic connotations seem to be sublimated into a corresponding form principle, that of intermediality, which is, in essence, also transformative in the way media change in the course of interaction. With identifying this correlation and regarding transformation as a political act, we step into the field of the politics of intermediality, where media effects become interpretable as performative acts beyond their pure artistic premises. Media tensions, convergences and reconfigurations, the desire for another medium can model transformation, in the language of art. ${ }^{3}$

The examination of intricate media interplays within film - and emphatically, with the medium of film - sheds light on cinema as a complex formation that is to be conceived in the in-betweenness of media and art forms. The Tango Lesson also creates multiple passageways in-between autobiography and fiction, art and life, the corporeal and the spiritual, the sacred and the profane, participation and observation, emotional involvement and professional detachment, creating a space "between-the-images" (Bellour 2012) that foregrounds manifold sensations of in-betweenness.

3 To the same extent as the essence of dance is change, change can also be grasped through the notion of dance. In outlining the contours of intercultural cinema, Laura Marks speaks of (political) change in terms of dance: "political (indeed any) change must be effected in a sort of dance between sedimented, historical discourses and lines of flight, between containment and breaking free" (Marks 2000, 28; emphasis mine). 


\section{From Dance in Film to Film as Dance. The Cine- Choreography of the Moving Image}

Cutting across genres and registers, from avant-garde and experimental art, through mainstream Hollywood productions, to arthouse cinema, perhaps no interart relation has been more explored than that of film and dance (see Dodds 2001; Mitoma 2002; Brannigan 2011). An homage to the Argentine tango, The Tango Lesson steps forth and back in that it simultaneously conforms to and deconstructs the genre of musical. On the one hand, it constructs a narrative interspersed with dance numbers, some of which are even reminiscent of classical dance scenes, such as the one on the bank of the Seine, evoking Gene Kelly and Leslie Caron's performance in An American in Paris (Vincente Minnelli, 1951), or the exhilarated tango moment in the rain, reminding of the elation of Gene Kelly with the rain as his dance partner in Singing in the Rain (Stanley Donen and Gene Kelly, 1952). In the way these scenes evoke the classics, the viewer perceives an unconditioned reverence to the classical symbiosis of film, music and dance that the musical genre represents in the history of film art. On the other hand, Sally Potter's film distances itself from the tradition of Hollywood dance movies, it deconstructs and transfigures the mainstream generic features into a metacinematic exploration that proposes to grasp the essence of film through the phenomenology of the tango, conjoining the body of the performer with the corporeality of the medium.

Dance scenes in The Tango Lesson are spellbinding in their diversity, from the first uncertain steps made in Pablo's studio to Buenos Aires milongas, back to the stage that brings failure and to redeeming the freedom of motion in improvised spaces. The lessons can be seen neither in terms of a Bildungsroman type of learning process nor in terms of a Hollywood-type advancement towards happy ending. They much rather indulge the viewer by scenes spontaneously and playfully morphing into dance, which are also characterized by a high degree of visual reflexivity. Such is the one in which Pablo is step-dancing and juggling with the salad in his home, where, at a certain point of his improvised performance before Sally's eyes, he dances in front of the mirror. Pablo's dance is framed into a cinematic sequence by Sally's “camera-gaze." His dancing figure is doubled by his mirror image, which can be interpreted as his screen counterpart in the heterotopic space of the mirror. [Fig. 2.] A similar degree of reflexivity can be identified in the scene in which the couple's walk and discussion at the bank of the Seine turns into an expression of joy in the form of dance. Through the 
intertextual reference to An American in Paris, the viewer is given the chance to perceive the image in its palimpsest-like, multilayered complexity and to exercise the skill of "seeing as." [Figs. 3-4.]

While Argentine tango is celebrated in the film in its self-containment, as a participatory art form allowing corporeal enjoyment mixed with profound spirituality, Sally Potter's film speaks about what film as a medium can add to dance, transforming the dancing body into the distinct corporeality of screen dance. The Tango Lesson dramatizes this transformation, bringing into play the mediality of both dance and film, and examining the way in which the interplay of the two results in a third, "othered" medium in which both dance and cinema are affected and transformed. In this way, the story of the relationship between the dancer and the filmmaker, their struggle for dominance and final reconciliation also gains signification as cinematic reflection on the intermedial relationship between dance and film. Once dance becomes part of the film, it loses the specificities of live performance and is reconfigured for the screen by cinematic techniques of mediation, which in their turn are modulated in accordance with the requirements of adapting to the expressivity of dance. Erin Brannigan calls this practice a dancefilm, which she defines as "a modality that appears across various types of films including the musical and experimental shorts and is characterized by a filmic performance dominated by choreographic strategies or effects" (2011, vii). She elaborates an interdisciplinary terminology that draws on both dance and film studies for what she calls cine-choreographies, including specific uses of movement, gestures, space, lighting, framing and editing, which "stage dance as one performative element within the cinematic field, often turning the films themselves into dances" (2011, 3).

For Sally Potter, film is dance. The spirit of dance lies at the core of filmmaking that she defines as "choreographing the relationship between the camera, the actors, and the space" (Ehrenstein and Potter 1993, 5). Watching The Tango Lesson, the spectator partakes in the embodied experience of the film that is not only about dance but also appears as a passionate tango itself. The impression of film as dance is created by the employment of dancefilm strategies throughout the film, which attests to the ways in which "dance and film work on each other" (Brannigan 2011, 8), resulting in a medial interface of dance and film, a tango-like "close embrace" and transfiguration of the two. The tango relies on the dynamics of preconstituted patterns - "basico" - and improvisations. Argentine tango, spectacularly characterized by the close embrace, is especially improvisational - this is why it presupposes a cooperating partnership. In the series of "lessons," 
the film "learns" to be the cooperative partner of the tango in that it resorts to a whole range of cine-choreographic procedures, which extend the impression of dance even beyond the dance numbers and the dancing figures. The way the spectacle of the dance is manipulated by the cinematic apparatus becomes visible from the very first dance number, which Sally follows from the public. The recording of the dance starts as a POV shot, the camera discretely moving behind Sally among the spectators, then it abandons the outsider's position and "gets closer" to the stage by the alternation of the field size of shots. In parallel with showing Sally's engaged gaze that works as a camera eye, it reveals closeups of the dancers' faces and legs, and finally lands, in the form of a medium shot, on the male performer's face, directly cutting out the female dancer from the image. This is the first controlling gesture on the diegetic filmmaker's part that also brings up the issue of gender difference coded into tango dance, showing the inseparability of the woman's and the filmmaker's gaze, echoed at the end of the film in Sally's replica to Pablo's reproach that she has become too impersonal, she has become a camera: "That's how I love you, Pablo. With my eyes. With my work." The entire reflexive apparatus operated in the film gains signification as part of the applied cine-choreographic strategy. Above all, introducing Sally's camera-gaze within the diegesis not only doubles the narrative layeredness but also reconfigures the medial perception of the moving image, since it reinforces the perception of the image as a framed image, of dance that actually does not exist on its own but only in the form of screen dance. While Pablo teaches Sally the gait and steps of the Argentine tango, Sally undertakes to teach Pablo to look, to step out of his narcissistic confinement as the embodiment of the unreflected spectacle, and to look at himself from the outside, as an image. Even in sequences that are not explicitly framed by Sally's gaze, the camera position orders the moving image into frames constituted by door frames, columns or other elements of the props, providing the sense of mediatedness and effecting the inseparable superimposition of dance as movement and as image. [Fig. 5.]

Together with Sally, the camera also participates in the learning process. Sally's first uncertain tango steps are recorded by a static, observing camera; it gradually becomes more and more involved and participatory, until it joins and gets carried away by the tango, passionately spinning and whirling together with Sally and Pablo on the public dance floor in Paris, among the dancing couples in the Buenos Aires milongas, or in the ravishing scene in the empty storehouse in Buenos Aires towards the end of the film, where Sally performs in rapture with Pablo, Gustavo and Fabian, and their performance is accompanied by Astor 
Piazzola's Libertango - the camera becomes the fifth aficionado that takes up the pace and rhythm of the tango. The alternation of the moving and occasionally also static camera is effected in line with a cine-choreographically paced rhythm, either reinforcing or counterpointing, but always organically interacting with the movement of the dance.

Dance scenes are recorded by alternating the field size of the moving image, with special attention to the micro-choreography of close-ups. Erin Brannigan examines "how the close-up in dancefilm creates a specific cine-choreographic order by extending and redefining the parameters and nature of screen performance and thereby extending the parameters of dance. This is achieved through an attention to the performing body and its micro-movements - the smaller detailed movements of the body and its parts. This can often produce a deterritorialization of the body so that any part of the corporeal whole can operate as a site for dance and, thus, meaning production and expression. Through these strategies, dancefilm institutes a bodily, dancerly model of the close-up that can operate even when the subject is not a moving body" $(2011,43-44)$. The Tango Lesson employs this model of the close-up by a special focus on recording the movement of the legs, which delight the spectator through their various forms of entanglement. Anne Jerslev discovers in the movement of the legs, "which without effort wind around each other in stylized and sensuous patterns" (2000, 284-285), the shape of the arabesque, an ornamental pattern that she extends upon the perception of the entire film texture. [Fig. 6.]

The impression of flow is created through the employment of matched-on action that ensures, through the continuity of motion, the smooth passage from one shot to the next one, just as in scenes when the dancing couple "moves" from private to public dance scenes. The dancerly quality is also the result of special ways of editing; the alternation of field sizes entails the adaptation of cuts to the rhythm and pace of tango steps. The freedom and exaltation of the Libertango scene is achieved by the travelling camera that accompanies the movement of the four dancers in the large space suddenly opening up for the tango. Travelling creates the impression of long take, however, there are jump cuts inserted in the sequence, in this way, the movement of the recorded tango is complemented with a sense of movement created by technical mediation. The entangled bodies and legs of the four dancing figures create a highly stylized, transcended image of dance, in which bodies perform in an ethereal state and in intercorporeal communion, in the sense Yeats's poem asks: "How can we know the dancer from the dance?" (Among School Children). 
The tango scene on the bank of the Seine can be taken as a perfect example of the way in which film demonstrates its transformative powers. The dancers are spinning along the riverside, surrendering themselves to the joy of dance as a form of lived togetherness and the dancers' organic oneness with the dance. The combined use of camera movement, dance choreography, lighting and space transforms the scene of spontaneous dance into an open-air stage lit by the reflectors of the passing ship, with the passengers on the ship representing the accidental public of Sally and Pablo's performed impromptu. Thus, the scene dramatizes the way in which dance undergoes "a sea change" within the medium of film. As such, it announces the public stage performance that follows later in the film, becoming its reflexive reduplication, just as everything in the film tends to find, in cinematographic terms, its partner image, resounding tone and reiterated motion. [Fig. 7.]

The scene of the public tango performance in Paris in which Sally fails to "follow" Pablo is recorded with cine-choreographic subtlety. The dance is recoded from the direction of the back of the stage, vis-à-vis the public and stage lighting, which has the effect of flattening the dancing figures and their performed motions into a shadow play, reinforced by the photographic quality of the blackand-white image. The onstage performance of the couple is complemented with the "dance" of floodlight and the long shadows of the figures on the stage floor as nonfigurative extensions of corporeal movement. [Fig. 8.]

The film abounds in reflexive extensions of figures in mirrors and other reflective surfaces. The heterotopia of the mirror signals the character being "elsewhere," not fully present, as if he or she were spiritually, emotionally lost for the other. Such is the reflection of Pablo in the dressing room after the above-mentioned performance, when during his fit of rage Sally feels he is a stranger to her. As a possible counter-image, the reflection of Sally's figure in the mirror of the elevator suggests that they occupy distinct spaces, their spiritual communion is broken. [Fig. 9.] The space full of chairs and mirrors, where Sally, Pablo, Gustavo and Fabian go after the Libertango dance provides an occasion for the multiplication of mirror reflections, distancing Pablo from the others by placing him on the other side of the mirror. He asks: "What do you see?" And Sally replies: "I see you in the screen." Pablo's mirror image suggests his screened virtuality, his becoming a moving image as perceived by Sally's agentic camera gaze. The great variety of mirror reflections creates, again, the impression of a cine-choreographic order underlying the filmic performance.

All in all, the cine-choreographic strategies applied in The Tango Lesson rely on the principle of modulation and variation, which also extend beyond dance scenes 
and dance movements. The travel among different locations - London, Paris and Buenos Aires -, the switch between English, French and Spanish, either motivated by diegesis or just as free circulation among languages, as the verbal experience of the other in the spirit of polyglot cinema, and even the elements of the setting and props, repeated with alteration, can be traced back to a cine-choreographic structuring principle that may be more or less linked to the mediality of dance.

The Tango Lesson is not only the "tango" of film and dance; somewhat similarly to the Libertango moment performed in four, qualities of several "partner arts," such as the photographic, the sculptural and the architectural, profoundly mark the experience of the film. The scenes that first depict the circumstances of a film in course of being made, entitled Rage, and then turn into the film itself, are shot in black and white radiating with digital gloss, while the embedded film project, remaining in torso, is also shot in radiating colour. In Sally Potter's filmmaking practice the increased emphasis on the plasticity of the image, on photographic composition, on the noir-ish intimations of light and shade, permeated by meaningful tension between the photographic quality of the single frame and the incorporating cinematic medium, results in an intermedial perception of the black-and-white image. The monochrome palette performs the transformation of the image from the initial white - the non-colour synthesizing all colours - as Sally, dressed in white, preparing to put on paper the first ideas of her film script, wipes clean the round-shaped white table in a white room - the white page containing all possibilities and directions a work may evolve into - to the nightblack of the final scene, colour of saturation, suggesting an accomplished image, a page fully written. In-between the white and the black, there is a range of infinite nuances of grey on grey, emanating sensations of rough and velvety, dreary and abounding, opening up the filmic image to multisensory perception that is also characteristic of dancefilm, transforming the eye into an organ of touch, as Laura Marks (2002) celebrates the return of the tactile in the haptic image.

The passionately immersive tango scenes are rhythmically counterpointed with sculptural moments of stasis, inserting stages of inertia as necessary parts in any creative-constructive process. Architectural forms such as the spiral staircase leading to Pablo's flat mould into artistic compositions. The architectural quality leaves its mark on the film in the locations alternating between Paris and Buenos Aires, which stand for various stages of transformation, from Sally's flat being in ruins, through the empty depository that is filled with and transfigured by dance in the Libertango scene, to the sacred space of the synagogue interior, where Sally and Pablo experience their conjoint, spiritual Jewishness. 


\section{Tableau Vivant as a Trope of Intermediality}

Intermediality can manifest in film through particular figurations that involve not merely “'an inscription' of one medium into another, but a more complex 'transfiguration,' in the process of which one medium gets to be transposed as a 'figure' into another, a figure of 'in-betweenness' that reflects on both the media involved in this intermedial process" (Pethő 2011, 78). In The Tango Lesson, the tableau vivant can be identified as such a figuration, deserving special attention.

The culminating intermedial moment of The Tango Lesson is the tableau vivant scene, in which Sally calls Pablo on the phone, tells him the biblical story of Jacob's wrestling with the angel and invites him to the Church of Saint-Sulpice in Paris, where Eugène Delacroix's painting Jacob Wrestling with the Angel (18541861) is displayed. Pablo arrives, and as a gesture of reconciliation he invites Sally to enact the wrestling figures represented on the painting. [Figs.10-11.] As they form a couple imitating the position of Delacroix's figures in a live tableau, fighting is dramatically transfigured before the viewer's eyes into the spectacle of dance, a posture of tango, while it also frames, in an accentuated moment of representational density, dance as fight, as experienced by the conflicting couple. The tableau animates the static painting while arresting the fluid continuum of moving images, thus becoming an intermediary zone of displacement, experimentation and reflection.

Pascal Bonitzer (1985) regards tableau vivant as a composite monster, a sphinx, an enigma. The biblical story is an enigma in itself, inviting the plurality of interpretations in the Jewish, Christian and Muslim traditions, in accordance with the identity that Jacob's wrestling partner is assigned: an angel, God, or another man. Jacob and the mysterious stranger wrestle all through the night, Jacob cannot be defeated and at dawn he remains with a wound on his thigh, is blessed and given the name Israel. Sally calls Pablo an angel at the beginning of the film, implicitly, she now places herself into Jacob's position and reveals her own failure by laying stress on Jacob's recognition of his own defeat. Thus the tableau scene represents a moment of self-realization in the face of the unfathomable other.

The tableau implies representational hybridity, the dialogue of painting, theatre and sculpture; in film, tableaux vivants emerge as tropes of intermediality, revealing the entanglement of different media that contribute to the heterogeneity of the moving image. Tableau moments in cinema are inextricably linked to the transition between art and life, representation and the "real," with significant 
differences in the theoretical conceptualization of this relationship. While Brigitte Peucker regards the tableau vivant as which "figures the introduction of the real into the image - the living body into painting - thus attempting to collapse the distance between the signifier and the signified" $(2007,31)$, Ágnes Pethó contends that "the tableau does not attempt to merge representation with the real and to collapse the distance between signifier and signified, but emerges as a site for cultivating their distance in the opposition of sensual form and abstract meaning, moving image and static painting, live bodies in action and objects contemplated as a visual display, framing their intricate plays of in-betweenness" $(2014,53)$. The tableau moment in The Tango Lesson may be illustrative of the latter: through the ambivalence of viewing the performed motions as duel and tango respectively, the live enactment does not merge into the signification of the artwork, but actually creates a hermeneutical distance by providing a new look upon it, while the artwork also creates a new horizon of understanding the protagonists' own situation as embodied experience. In this way, the tableau scene becomes a subtle study of motion - as regards interpersonal relations as well as media entanglements. An homage to both the art of dance and the art of film, and also a vision of their interconnectedness, the tableau vivant in The Tango Lesson, staged in a sacred place, is a heightened sequence with dramatic effect and signifies a turning point in the diegesis, as it leads out of the crisis. As Sally has been following Pablo in the tango, now the filmmaker asks for the dancer's willingness to follow. The stasis of the tableau freezes the couple into a living picture, which is already the territory of visual arts. Undoing, reducing the dancers' choreographed motion to a standstill, in the spirit of the tradition of tableaux vivants, represents a sort of protocinematic moment, the syncretism of the arts. The filmmaker's regaining the terrain of the visual is also marked out by the picturesque spectacle: the viewer's gaze is caught between Delacroix's elaborate design and the stylistic purity of the enacted live tableau, delighting in the sensation of its heightened, symbiotic imageness.

\section{Conclusions. From Paragone to Symbiosis}

In the abundance of dance numbers combined with narrative scenes, in Paris and Buenos Aires, onstage and offstage, inside and outside, emotionally involving and tenderly parodied, performed with ease and with struggle, in euphoria and in tension, the viewer witnesses the miraculous transformation of dance into screen dance, and the birth of film in profound interlacement with dance and 
the other arts. Sophie Mayer states that “in Potter's work cinema is celebrated as an artform capable of making change because it incorporates all the arts without losing its specificity" $(2009,3)$. It can be added - with a slight shift of emphasis - that it is through the reflection of the other medium, through film's capacity to "follow" the other arts that film can reveal its own innermost medium specificity.

The intermedial relationship between dance and film is not devoid of tensions either. As Brannigan remarks, "the tendency of dance toward unrestrained, hyperbolic motility and unexplained stasis, and film's tendency to order, restrain, frame, and cut, work upon each other in dancefilm to produce limitless variations and experiments that test the limits of cinematic production" $(2011,15)$. The medial tensions and conflicts become interpretable in the sense of paragone, film's "wrestling" with the other arts, which undergoes a transformation to be finally dissolved into an - almost utopian - symbiosis, "close embrace" of arts, a dance of intermediality, ultimately reducible to the same principle: that of solidarity. Sophie Mayer notes that "The Tango Lesson ends, with its characters and the film itself transformed through the 'inner exchange' of tango's improvisation and collaboration" (2009, 20). The Argentine tango, performed by Sally and Pablo, experienced in its haptic profusion, gives way for a profoundly personal and at the same time highly professional cinematic achievement relying on the principle of cine-choreography inspired from dance. Sally Potter is also interested in the cosmopolitan nature of the tango, as a shared heritage beyond nations and ethnic groups, which belongs, without discrimination, to the one who performs it, becoming a way of perceiving the other - subjectivity, language, medium, culture - as an embodied experience. In the film, tango emerges as a site of negotiating roles and levelling identities, resulting in the profound solidarity and friendship of the Argentine Jewish tanguero, afraid of disappearing without leaving a trace, and the British filmmaker, demonstrating her "feel[ing to be] a Jew" through her ethics of listening and openness towards the other. Sally and Pablo transcend their gender differences and experience their transformed selves through the encounter and spiritual communion with the other, becoming one in Sally's final song - "You are me and I am you, / One is one and one are two." Just in the same way, dance is sublimated into film and film is transfigured into dance, becoming one through dancefilm practices, in the process of intermedial transformation. 


\section{References}

Bellour, Raymond. 2012. Between-the-Images. Zürich, Dijon: JRP Ringier \& Les Presses du Réel.

Bonitzer, Pascal. 1985. Décadrages - Peinture et Cinéma [Décadrages - Painting and Film]. Paris: Cahiers de Cinéma, Éditions de l’Étoile.

Brannigan, Erin. 2011. Dancefilm: Choreography and the Moving Image. New York: Oxford University Press.

Canudo, Riciotto. 2002 [1911]. The Birth of the Sixth Art. In The European Cinema Reader, ed. Catherine Fowler, 19-24. London and New York: Routledge.

Dodds, Sherril. 2001. Dance on Screen: Genres and Media from Hollywood to Experimental Art. Houndmills, Basingstoke, UK: Palgrave.

Ehrenstein, David and Sally Potter. 1993. Out of the Wilderness: An Interview with Sally Potter. Film Quarterly vol. 47, no. 1: 2-7.

Fowler, Catherine. 2009. Sally Potter. Urbana and Chicago: University of Illinois Press.

Guano, Emanuela. 2004. "She Looks at Him with the Eyes of a Camera": Female Visual Pleasures and the Polemic with Fetishism in Sally Potter's Tango Lesson. Third Text: Critical Perspectives on Contemporary Art and Culture vol. 18, no. 5: 461-474.

Ince, Kate. 2012. Feminist Phenomenology and the Films of Sally Potter. In Existentialism and Contemporary Cinema: A Beauvoirian Perspective, eds. Jean-Pierre Boulé and Ursula Tidd, 161-173. New York and Oxford: Berghahn Books.

Ince, Kate. 2017. The Body and the Screen: Female Subjectivities in Contemporary Women's Cinema. New York; London: Bloomsbury.

Jerslev, Anne. 2000. Sally Potter's “Ecrands Seconds”. A Reading of Sally Potter's Work. Nordicom Review no. 2: 275-290.

MacDonald, Scott. 1995. Interview with Sally Potter. Camera Obscura no. 35: 187-221.

Marks, Laura U. 2000. The Skin of the Film: Intercultural Cinema, Embodiment, and the Senses. Durham, NC: Duke University Press.

Marks, Laura U. 2002. Touch: Sensuous Theory and Multisensory Media. Minneapolis: University of Minnesota Press.

Mayer, Sophie. 2009. The Cinema of Sally Potter. A Politics of Love. London and New York: Wallflower Press. 
Mitoma, Judy, ed. 2002. Envisioning Dance on Film and Video. New York: Routledge.

Mulvey, Laura. 1999. Visual Pleasure and Narrative Cinema. In Film Theory and Criticism: Introductory Readings, eds. Leo Braudy and Marshall Cohen, 833844. New York and Oxford: Oxford University Press.

Paech, Joachim. 2011. The Intermediality of Film. Acta Universitatis Sapientiae: Film and Media Studies vol. 4: 7-21.

Pethő, Ágnes. 2011. Cinema and Intermediality. The Passion for the In-Between. Newcastle-upon-Tyne: Cambridge Scholars Publishing.

Pethő, Ágnes. 2014. The Tableau Vivant as a “Figure of Return” in Contemporary East European Cinema. Acta Universitatis Sapientiae: Film and Media Studies vol. 9: 51-76.

Peucker, Brigitte. 2007. The Material Image: Art and the Real in Film. Stanford, California: Stanford University Press.

Simonson, Mary. 2013. Body Knowledge: Performance, Intermediality, and American Entertainment at the Turn of the Twentieth Century. New York and Oxford: Oxford University Press.

\section{List of Figures}

Figure 1. The filmmaker's "camera eye" looking at the male dancer, reversing the stereotypical female role of "to-be-looked-at-ness." The Tango Lesson (Sally Potter, 1997).

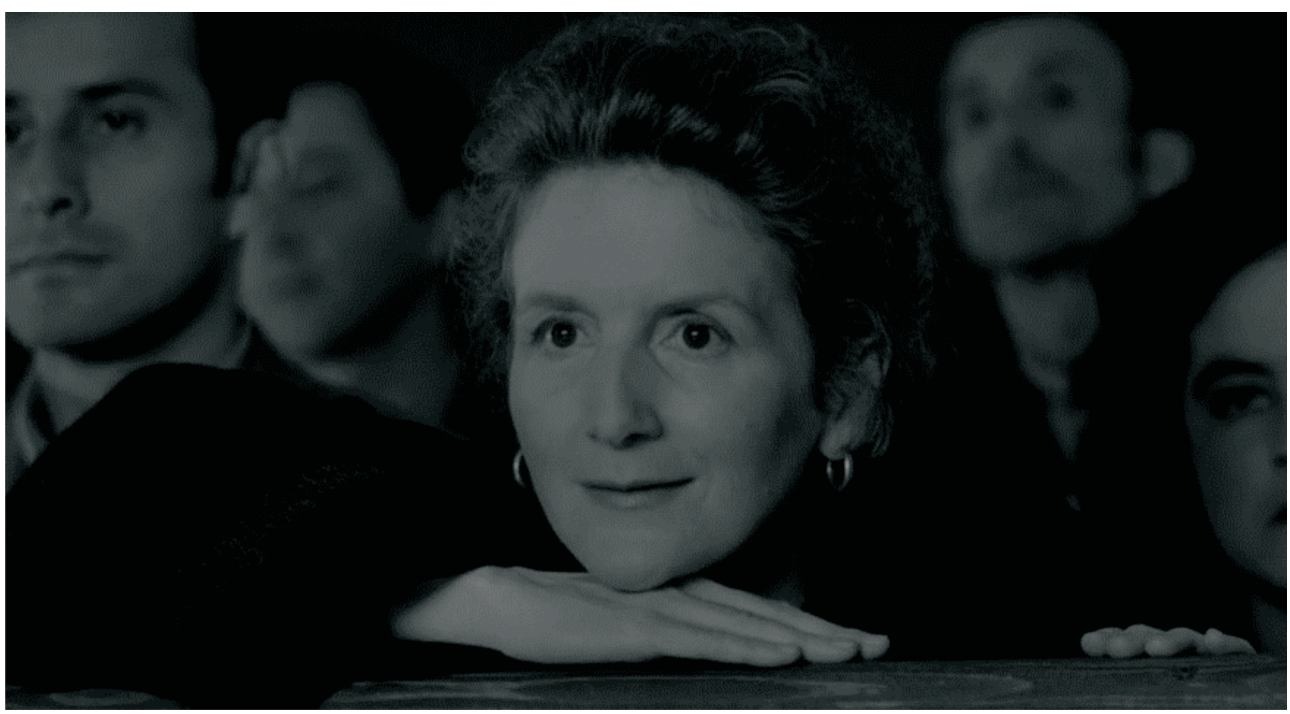


Figure 2. Pablo's dance with his mirror image as an instance of visual reflexivity. The Tango Lesson (Sally Potter, 1997).

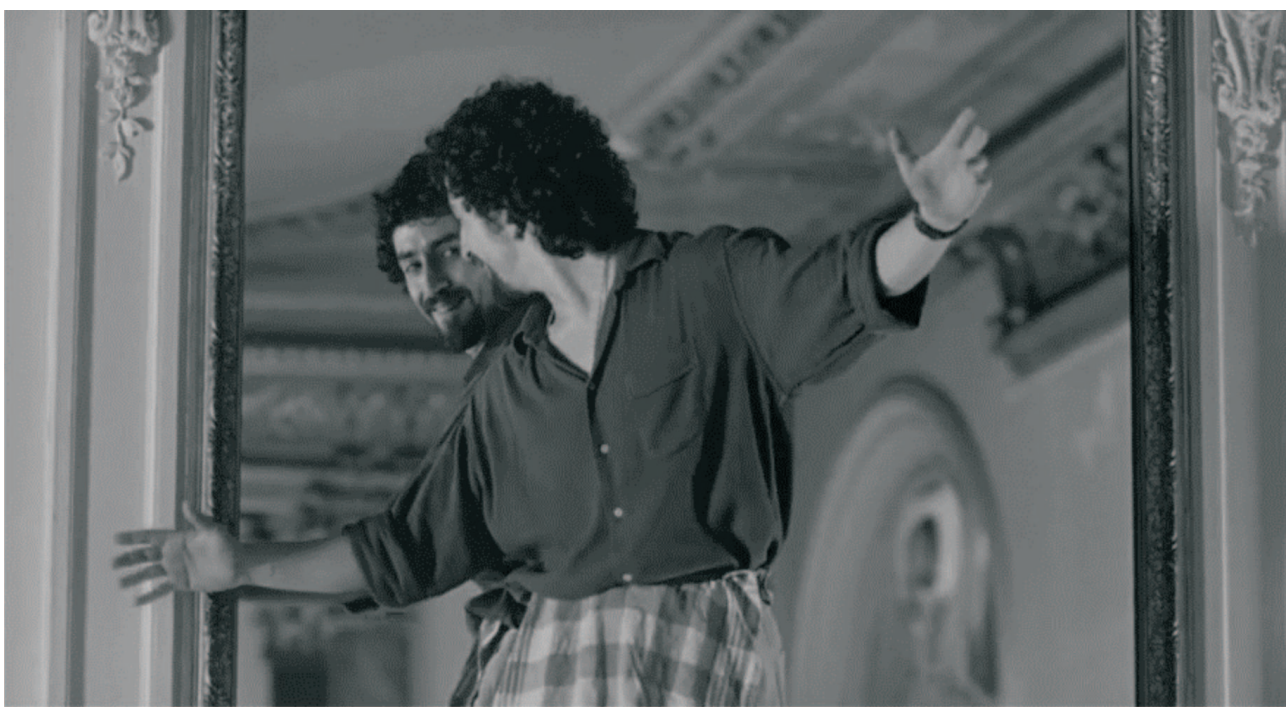

Figures 3-4. Dance numbers set at the bank of the Seine. The Tango Lesson (Sally Potter, 1997) and its intertextual reference, An American in Paris (Vincente Minnelli, 1951).

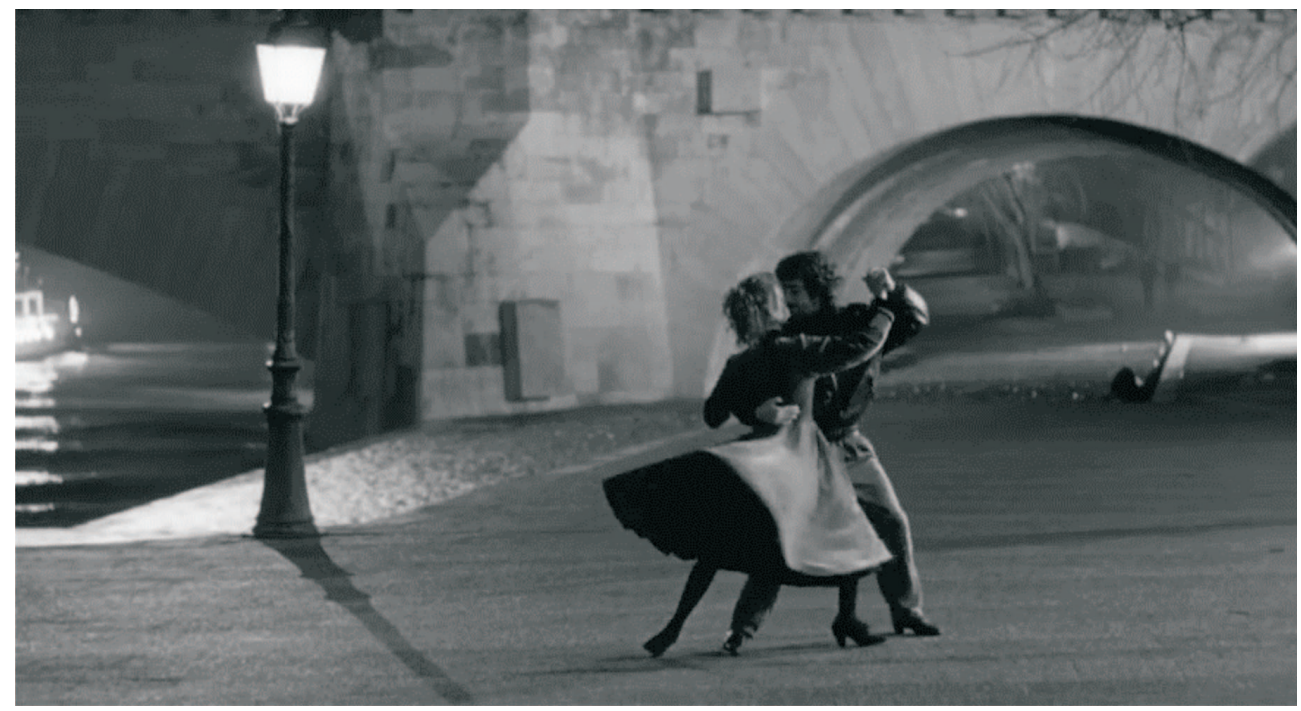




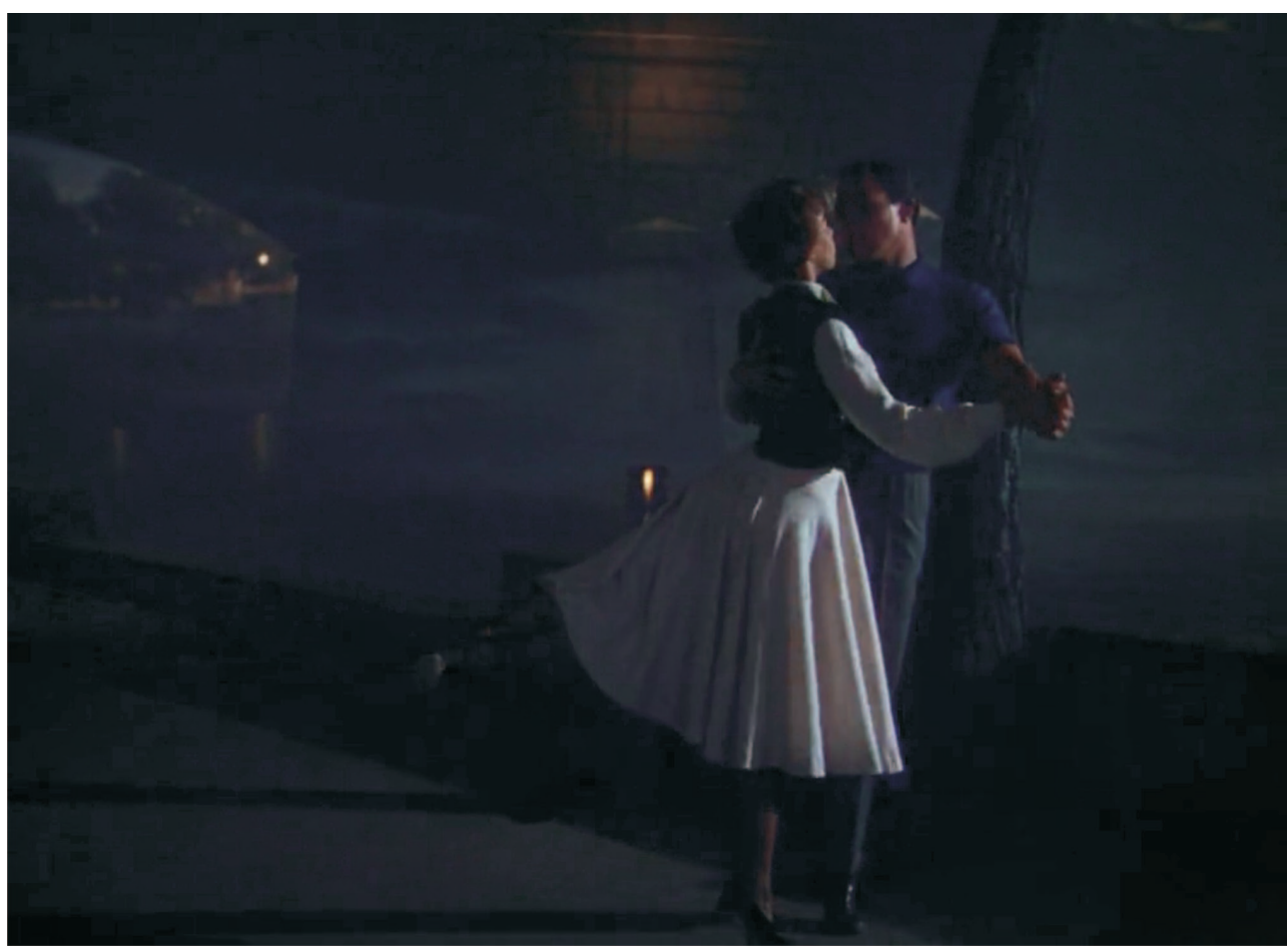

Figure 5. Framing the moving image. The Tango Lesson (Sally Potter, 1997).

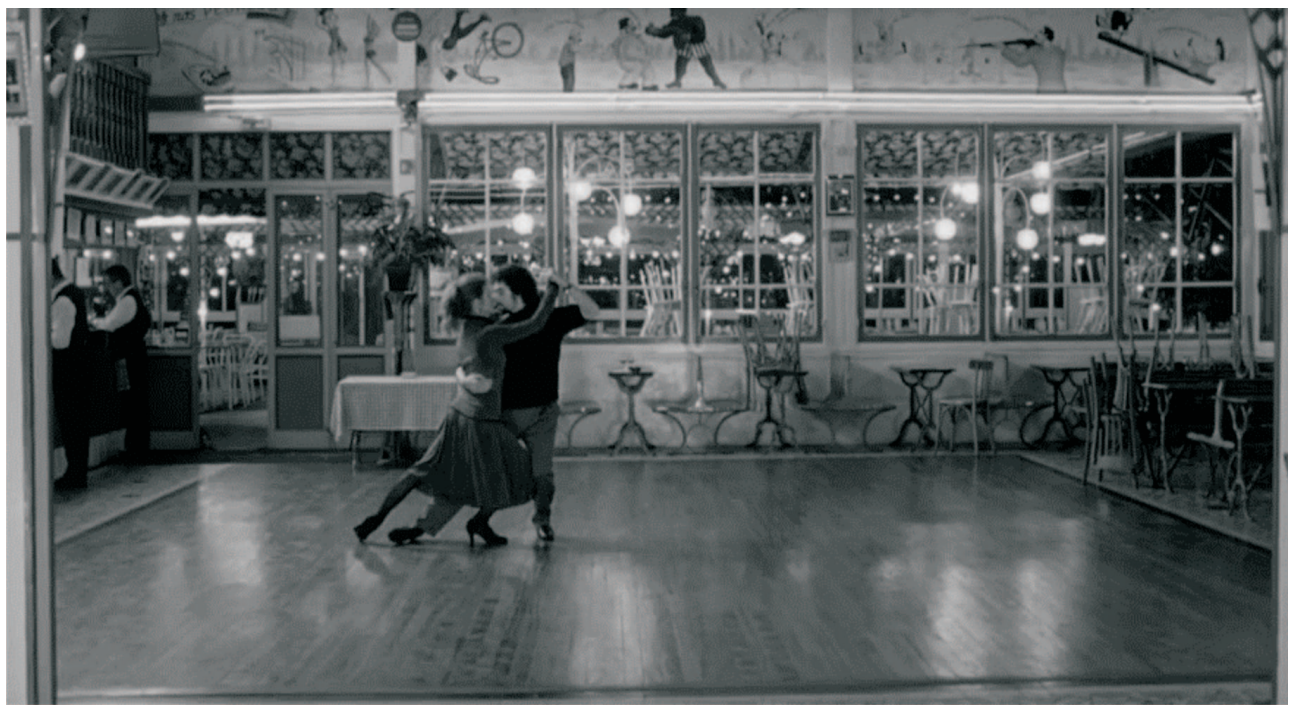


Figure 6. Micro-choreographies of the tango captured in close-ups. The Tango Lesson (Sally Potter, 1997).

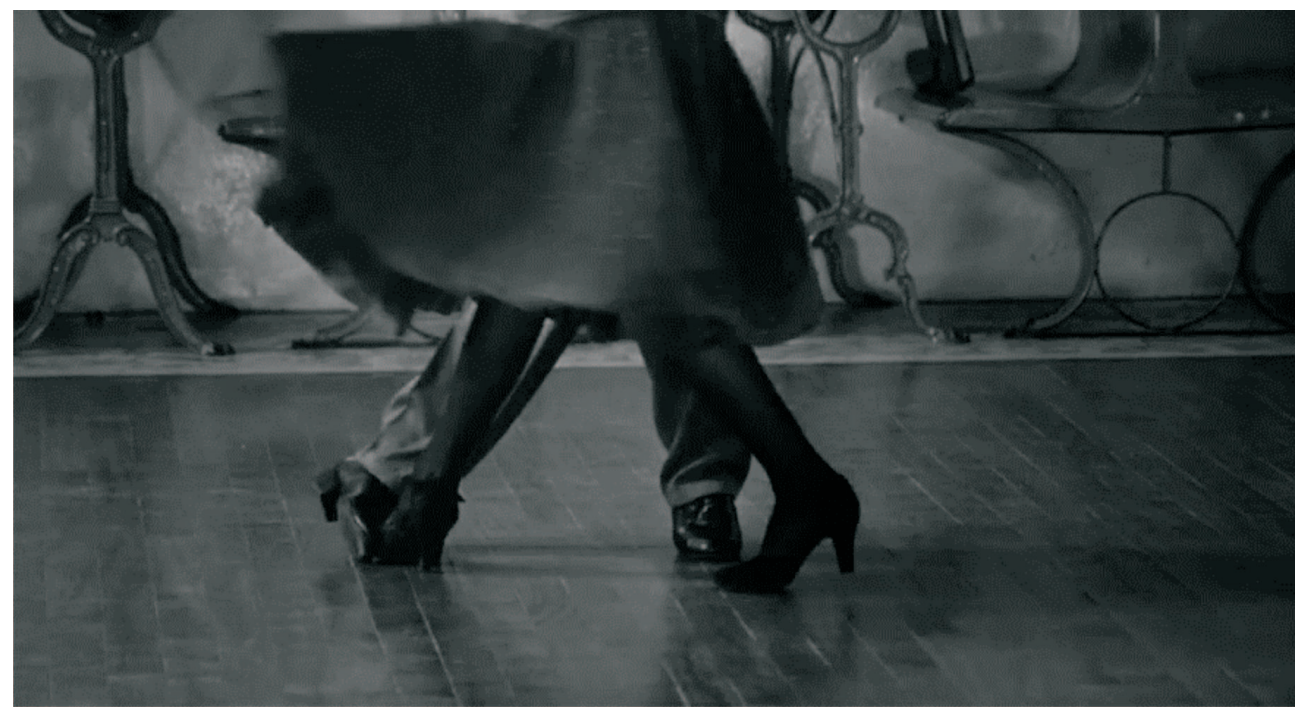

Figure 7. Cine-choreography turning dance into screen dance by filmic performance. The Tango Lesson (Sally Potter, 1997).

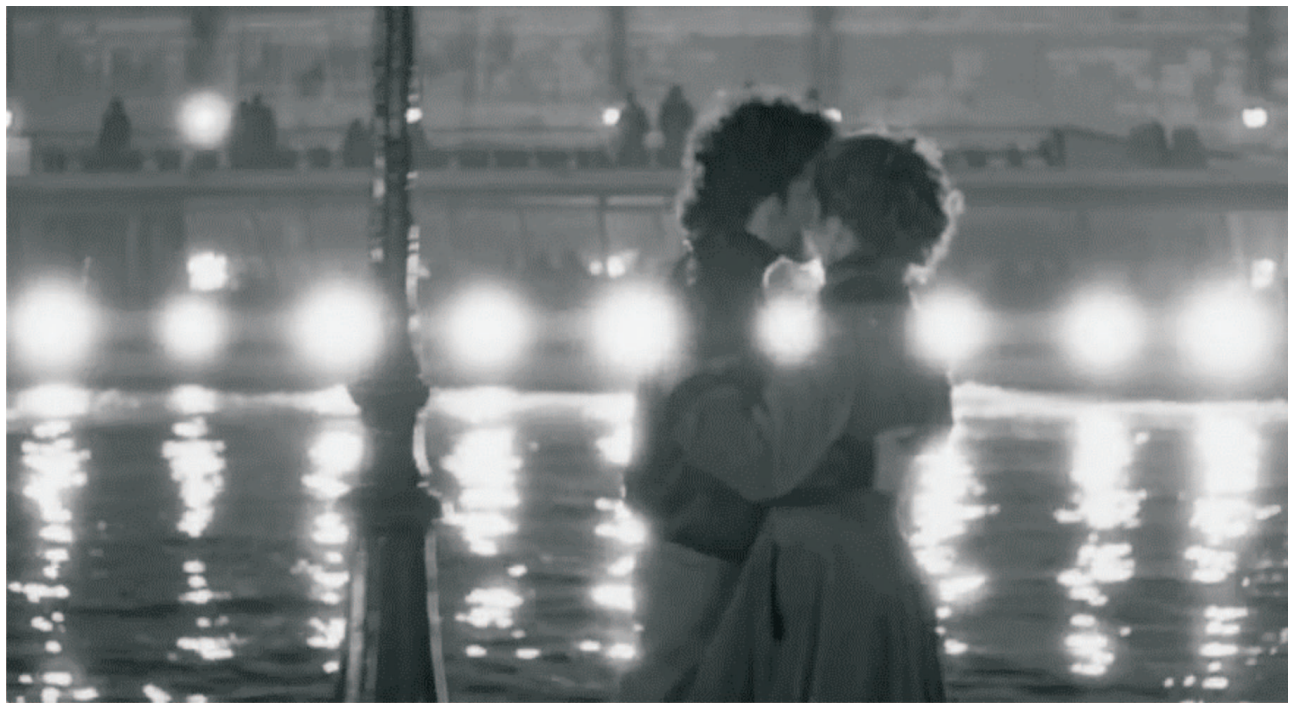


Figure 8. The dance of light and shadow as the extension of corporeal performance. The Tango Lesson (Sally Potter, 1997).

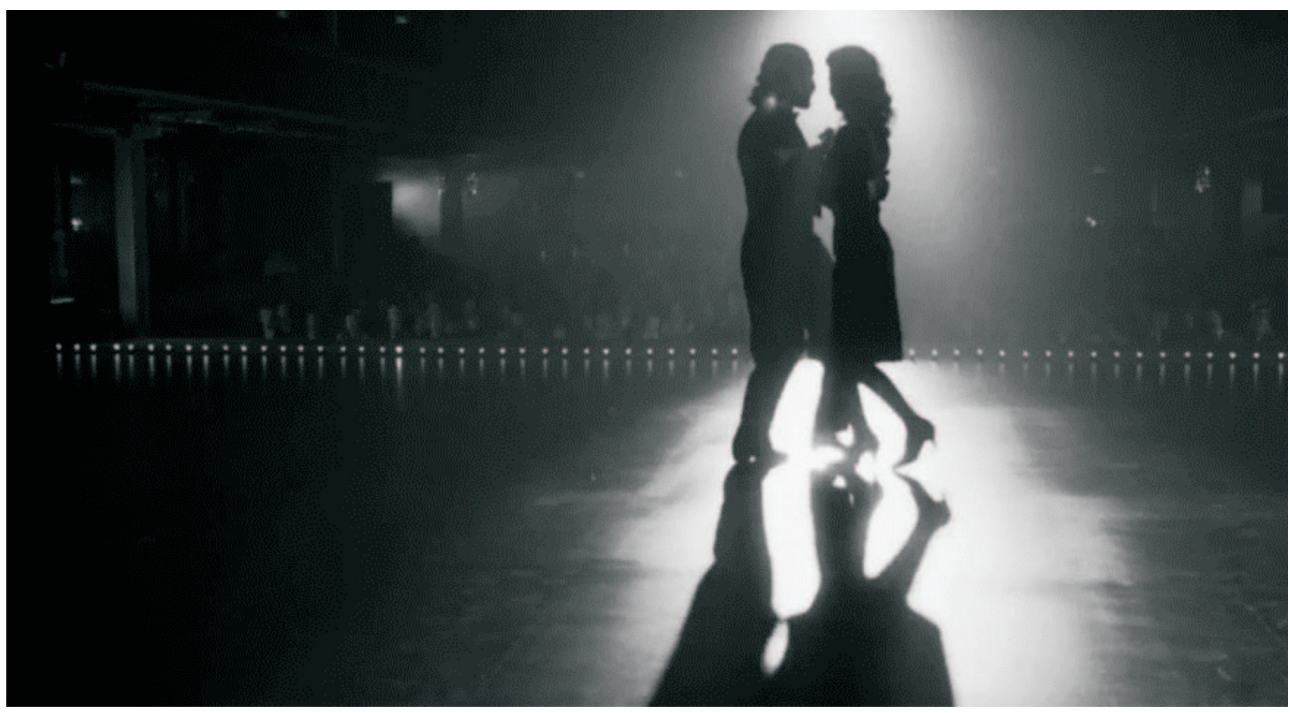

Figure 9. The heterotopia of the mirror reflecting the broken communion between Sally and Pablo. The Tango Lesson (Sally Potter, 1997).

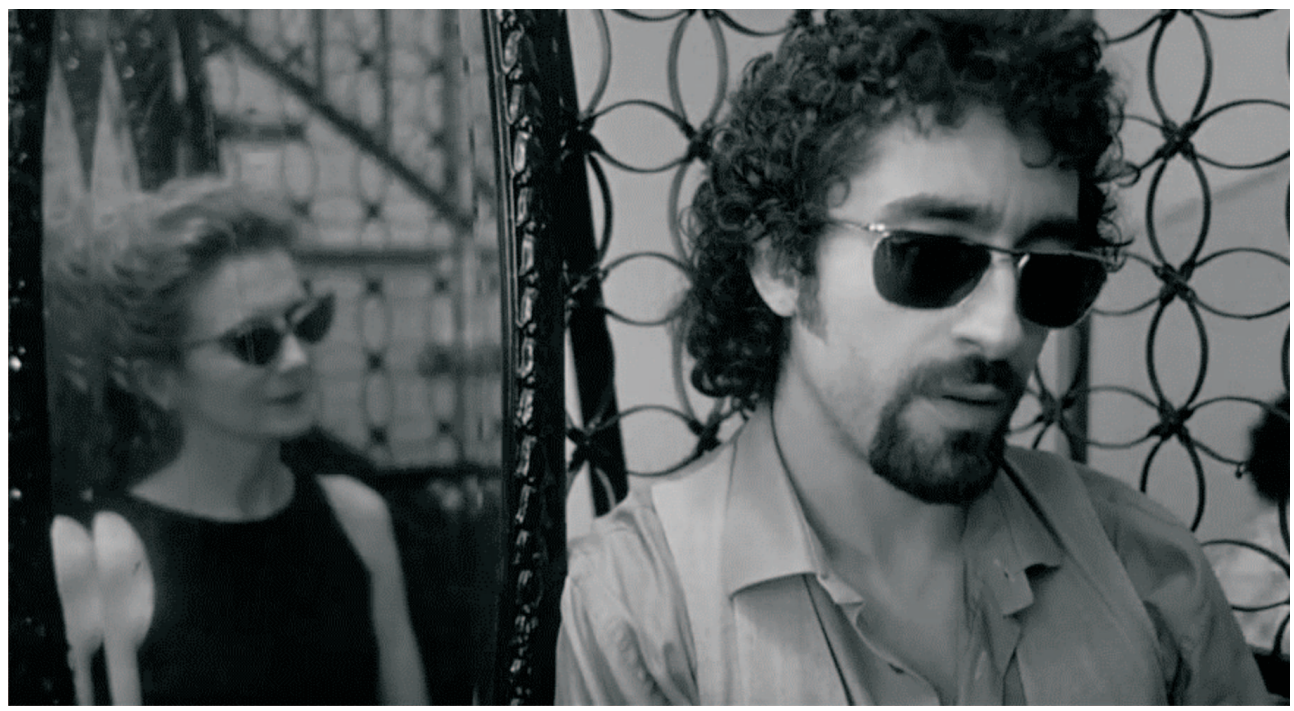


Figures 10-11. Sally and Pablo enacting, in a tableau vivant (The Tango Lesson, Sally Potter, 1997), Delacroix's painting Jacob Wrestling with the Angel (18541861).
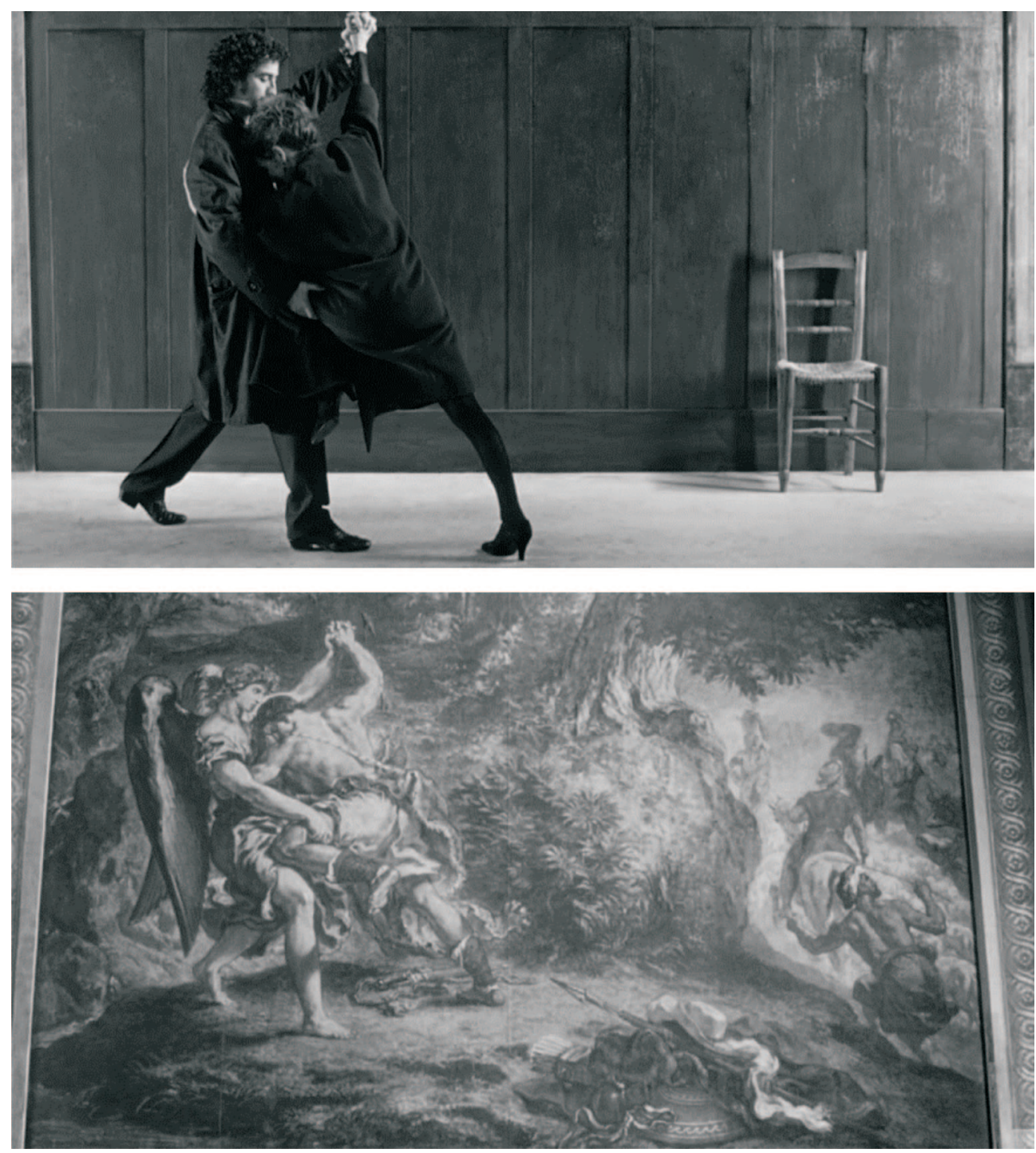